\title{
Chaos Theory as Relevance for Engineering Education in the Era of the Fourth Industrial Revolution in Africa
}

\author{
Kehdinga George Fomunyam
}

\begin{abstract}
In the fourth industrial revolution (4IR)period, an inclusion of Chaos Theory (CT) in Engineering education (EE) and its significant relevance have involved debates from engineering academia and industrial professional over the years. Thus, much has been done to recall relevance for $\mathrm{EE}$, yet $\mathrm{EE}$ has not attained Sustainable Development Goal for educational target, in areas of research relevance, curriculum restructuring, and learning materials/instructional platforms redesigning are still lacking in engineering academia and profession in Africa. With much sensitization on inclusion of $C T$ to instil $E E$ relevance in Africa, is still far from addressing EE gaps; hence the crux of this paper. This paper was guided by Chaos theory providing definite perception which involves equilibrium constructs that are crucial in EE. This paper focused on the concept of CT as its relevance in $E E$ in the4IR in Africa. In particular, it explores how $C T$ can enhance relevance in $E E$; and how the principles of $C T$ can improve the $E E$ relevance, as well as its implications in Africa. Thus, to address these gaps, recommendations such as developing nonchaotic curriculum for EE, adopting Chaos theoretical principles in facilitating staff training and students' skill development were advocated.
\end{abstract}

Keywords: Africa, Chaos Theory, engineering, relevance,

\section{INTRODUCTION}

The global population statistical figures has showed that the world population was estimated to grow from six to exceeding nine billion people between 2019 and 2050, as eight out of nine billion persons will be found in lowincome nations in sub-Saharan Africa, Asia, and Latin America, whose fiscalprogress is anticipated to some extentnot more than high income nations(WEF, 2017). As these developing countries have presented future society with enormous challenges on many facades, encountered with vulnerability and inability to address these issues plaguing them. These challenges involve solutions that create stability inhi-tech innovation, and aiming to maximize fiscal gross domestic product as well as viable markets. In order to fathom and provide solutions to address these issues, approaches to these problems requires holistic, flexible and adaptive, as well as integration of many diverse opinions and interests from relevant stakeholders both at the national and international levels (WEF, 2009; 2017). However, accelerating engineering educational revolution is on the edge of an era of irremediable change in technology, in which new ways of engineering experts has been made available in fourth industrial revolution (4IR)period.

Revised Manuscript Received on October 25, 2020.

Dr. Kehdinga George Fomunyam*, Institute for Systems Science, Durban University of Technology, Durban, South Africa.

(c) The Authors. Published by Blue Eyes Intelligence Engineering and Sciences Publication (BEIESP). This is an open access article under the CC BY-NC-ND license (http://creativecommons.org/licenses/by-nc-nd/4.0/)
This exponential growth and fusing of engineering discoveries in 4IR era has brought revolution in EE (ChanHilton et al., 2019; Secules et al., 2018). The giganticphases of thesystematic and theoretical invention in EE are consequentlyprojected to intensify, as part of engineers and engineering scientists, isperquisite in building theoretical novelties. The transitional stages in engineering career has exposed engineering students at present to operate as a experts, integrators and modernizersin creating philosophical knowledge-based and skill development in an industrial fields(Al-Atabi, 2014; Goldbery et al., 2014). For they need cross-cutting capabilities and an open minded-set beyond technical expertise to link EE to theoretical constructs such as Chaos theory (CT). Thus, the complexity theory was established with thenode of numeroussystematic and its expected values, as it was deep-rooted in Mathematics' Chaos theory. CT emphasized that even some deterministic systems were complex with unpredicted behaviours. This intricacy arises because different systemicfeatures act upon one another in ways that cannot be specificallyexhibited(Wang et al., 2012; Boeing, 2016). Nevertheless, CT has created behavioural practices that are influenced in envisaging the course of a complex system. Complex systems theory diverges from CT, which elucidate the systems of knowable outcome that are in position to adjust in randomtechniques within a system to act together with one another to spawn change. Thus, CT built on elements such as structures, fractals, preliminary effects, and divergences, that are applied to learning in an engineering institution(Graham, 2012; Iqbal et al., 2014; 2015). CT is reflected in learning holistic, constructive, and dynamic; as relevance of CT to classroom will enhance learning in strengthening systemic approaches to human interactions (References). This will go a long way to encourage traditional constructive teaching and reasserting theoretical notions of multi-dimensional dynamics without linear progression. CT cannot be applied to human learning systems, but can be suggested as social constructivism, as asuitable model for relevance in EE in Africa (Grasso et al. 2010). In Africa, the dimension of CT relevance in EE requires engineering academics and students to be concerned in developing rational thinking of creating relevance of CT in modern EE. As this ranges from justifications in identifying the working principles of $\mathrm{CT}$ in building EE relevant in 4IR. Hence, this paper presents a systematic review which explore CT relevance for EE in 4IRE in Africa.The systematic review method adopted in this paper identifies and appraise published articles from year 2009 to 2020 in the fields of Engineering, Education, Mathematics, Geography systematically.

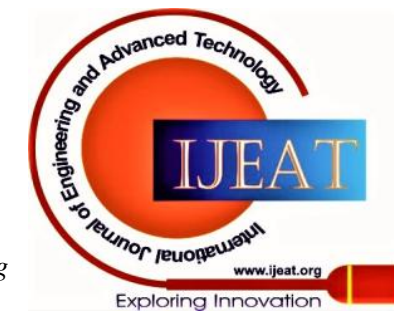




\section{Chaos Theory as Relevance for Engineering Education in the Era of the Fourth Industrial Revolution in}

Africa

This was to appraise published reviews on the study objectives and to discuss its implications with recommendations. The broad aim of this paper is to fill the research gap by contributing to the overall understanding of the principles of CT relevance for EE in 4IR in Africa. Specifically, we explore how CT relevance enhances EE; and to examine the principles of CT relevance, and it works to improve EE, hence recommendations were advocated.

\section{THE RESEARCH GAP}

The education of 4IR of engineers is beginning to adopt CT to attain relevance in EE, as significant efforts are needed to address quality gaps in $\mathrm{EE}$ as well as in the profession (Lucas, 2014; Ouchinnikov et al., 2016). This was made to instill CT in engineering perspectives as well as adopting the tenets of curriculum programmes and learning instructional materials in EE. This aid in raising realization in CT relevance for EE in Africa (Eduards et al., 2012; Al-Atabi, 2014). Yet, there is a growing concern in adopting the principles of CT relevance for EE, with a worrying reflection, as 4IR debates on CT relevance for EE cannot be secluded from wider engineering teaching and learning platforms in Africa. Hence, there is a clear discrepancy and a wide gap in EE interrogating EE curriculum and instructional materials, associated with sidelining the use of CT in their day-to-day teaching and learning in engineering classrooms (Akmansoy et al., 2014; Chan-Hilton et al., 2019). The fact remains however, that the debates on the relevance of CT for EE cannot be isolated from disparities in other disciplines' interplay with theoretical models; hence the crux of this paper. The critical questions are: What is the overall understanding of the principles of CT and its relevance in EE in 4IR in Africa? How does CT add to the relevance of EE? What are the principles of CT and how it works to improve the relevance for EE? What can EE do to address the gaps in order to rebuild the principles of $\mathrm{CT}$ in EE? What are the recommendations of CT's relevance in addressing these gaps in EE in Africa? The answer to these questions are critical, urgent and unavoidable by all stakeholders within or outside engineering institutions, hence recommendations were advocated.

\section{METHODOLOGICAL APPROACH}

Systematic review method was used in this study as the author derived questions from knownrelated studies using the study objectives. The studies were sampled to fit in the annexation measures to ascertain the quality of the research paper, as well as the use of an unequivocal approach (Gough et al., 2017). Significant studies were categorise using the study research questions through reviewed articles archives. The descriptors "CT", "CT in engineering", "CT in EE", and "relevance of CT in EE" were used to find the key bases. The permutation of the descriptors such as "global", "USA", "developed countries", "developing countries" and "Africa" was employed as an under-stated factors in EE (Borrego et al., 2015). Several papers were considered as prospective basis of qualitative data(InêsDoreito et al., 2019), however, quality papers with the criteria were reviewed as follows: (I) in print from 2013 to 2020; (II) explored how CT enhances relevance for EE in Africa as one of the lenses for analysis; and (III) examined the principles of $\mathrm{CT}$ in improving the relevance for $\mathrm{EE}$ in Africa. Again, the papers were allocated into sub-sections relating to study objectives and identified types of analytical themes in sampled articles were itemized. In total, there were 45 reviewed articles indicating systematic review articles. Of those articles, only 35 articles clearly that were identified with the theme ' $\mathrm{CT}$ and its relevance for $\mathrm{EE}$ in Africa' were used. The other ten articles simply specified more of 'thelogical theoretical papers'. To recap the validation found in these sampled articles, appraisal of the sampled articles was completed, along with a developed coding sheet. These identified grouping on the coding sheet involve study's objectives, research questions, methods, type of data collected, study population, and relevant findings. Also, methods used to evaluate and review published articles scientifically, were drawn from existing studies (Gough et al., 2017; Torres-Carrion et al., 2018;). Logical research practices were approved as reporting of logicalappraisals was clearlyelucidated. After review, the principal investigator combined the initialoutcomes and designs recorded in summaries. The author reviewed these summaries based on the preliminary outcomes to guide the concludingassessment of the sampled articles. After the sampled papers were analysed, the principal investigator established a typical sampling framework in which the articles were used to outlined the studyenquiries. These illustrative samples were not taken verbatim, but rather synthesized to illustrate how analytical research in EE can reframe to redefine key themes and research questions in CT and its relevance for EE (Brown et al, 2015). In addition, identifying and appraising the process of published reviews allows researchers to describe the quality of compiled existing studies, summarize and compare the conclusions of the reviews as well as discussing the implications and recommendations of the reviews (Gough et al., 2017). The principles of systematic review methodology were emphasized in studies that explore how the principles of CT can be rebuilt in the EE curriculum and learning materials will primarily address the gaps in EE in Africa (TorresCarrion et al., 2018). In the discussion section, an outlined descriptive research questions were presented around the reviews that were systematically analysed.

\section{LIMITATIONS}

While this study focused on published articles in relation to CT relevance for EE in 4IRE in Africa,there is likelihood that authors may have exclude significant reviewed articles that focused on CT relevance within social contexts of EE areas of research. Furthermore, selected publications from 2009 to 2020 were enlisted, however the authors may have excluded earlier studies that centred on CT relevance for EE in Africa. The emphasis of the research objectives was to study the contemporary studies on CT relevance for EE.Lastly, the reviewed articles employed quite a lot of rational

Published By:

Blue Eyes Intelligence Engineering

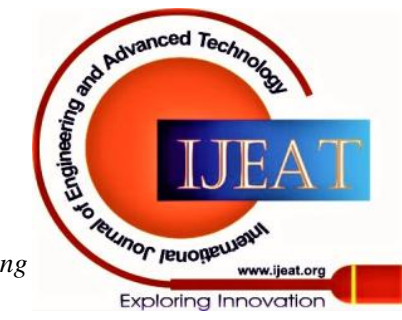


hypotheticalcontext and the selected reviewed articles utilized no less than one logical context.

\section{LITERATURE REVIEW:}

In the 4IR era, technology advancement and clear flop in the fields of engineering linear modelling is becoming visible, as several other substitutes have been investigated and confirmed in non-linear dynamic systems in EE. Thus, CT is one the numerous options that provide new understanding in EE. CT, as theoretical knowledge, comprises of hypotheticalrudiments which include systems that has a repeating geometric pattern, with preliminaryengineering phenomenon, and divergences(Nehmzow et al., 2005; Okulov, 2020). These elements are usually aligned with CT concepts that are not in direct proportion with randomness, which direct Chaos theoretical interpretation of EE ideas. Such ideas are irreversible processes that can create order, which is far-from-equilibrium conditions that can cause bifurcations, and entropy, that triggers the dominant literature in engineering research and reading materials (Juarez, 2011; Beanland et al. 2013).For it requires a strong model that validates engineering system applications for CT to employ the hypothetical principles in EE. However, EE has been given a priority in industrial engineering, due to general variations worldwide.In engineering modelling occurrences, numerous methods have been put on collective apparatus involving factual lifecycle, as society changes The engineering profession is indefinitely connected to development and growth, where the interconnection is neither simple nor linear (Wolf-Branigm, 2015; Graham, 2012). This is the reason CT has been used as a suitable algorithm for modelling and describing the non-linearity of EE phenomena.Besides, CT is not only anintricate occurrenceof hypothetical interpretation, but also from a logicalaspect,establishing an existing sets of variables that are fixed in the output of an engineering materials (Lucas, 2014). EE provide social environments that allow greater challenges in engineering fields as its assessments goes with anunderlying forces and impetuosity with little and persuasive time series. That is one of the mainexplanations of switching from anarchetypalundeviatingmethod from the sequence of engineering technicalities to a non-linear chaotic approach which is concerned with the relevance of CT in EE (Werndl , 2009; Wang et al., 2012). Therefore, there should be a proper and clear distinction between randomly and predicted numbers that make availablestagesput forward to the strong basis for the relevance of CT in association with the research study and observed policy actions. Also, CT has provided alternative ways for engineering profession to thrive with 21st century skills to gain relevance in the 4IR era in Africa, even though being faced with unplanned factors. Engineering research has too many variables, impellingtechnologyadvancement to be unified in a deterministic model, with an indistinct predisposition, whichspawns biases in EE (Goldberg et al., 2014). Conversely, linearize technical models has been used in engineering in decades, starting from postulation that logical solutions can be acquired, given the direct proportionality amongst variables' changes and some degree with rapid evolution of economic growth and development.

of projection errors in engineering (Chan-Hilton et al., 2019). Although, that was not always the case for other disciplines outside engineering and consequently, is such a non-deterministic system that has been categorized as multifaceted or uniformdisordered. Hence, the display structure of chaos theoretical models may start from the unassuming non-linear equation, although several deviations might influence unavoidably composite in engineering systems(Iqbal et al., 2014; 2015). For the research area of phenomena in EE, and perhaps one feature of non-linearity is suitability, that requires intensifiedapproval of aptmethod. This becomes a major concern in formulatingassumptions of time continuity in policy-making (Secules et al., 2018). For EE, which could be rather periodic under definiteconditions and its purpose, was to get abridgeddemonstrations of the complex system of behavioural outcomes that stimulates systematic arrays.Here, CT is very useful, as it ismostly attached to non-linear deterministic connections with its significant role in EE (Englund, 2009).Chaotic systems seem to be unpredictable, presenting themselves with variables that provide un-proportional outcomes in contrast with induced deviations, that are in fact, and deterministic, in nature. The EE system has a connectingimpellingaspects, as 'deterministic chaos' is as a consequence, of the real chaos in exceedingly complex engineering structures. The predictable outcomes of the complex natural systems obeys rules that are routinely seen as the overalllikelihood,except that,increases ananalyticalinfluence in enabling temporary decisional procedure in engineering (Wolf-Branigm, 2013; Lucas, 2014). The chaotic approach provides EE the prospect to precisely predict theprobableconsequences of, engineering chaos, which is still a significant issue in Africa (Eduards et al., 2012; WEF, 2017). Further, in building the relevance of $\mathrm{CT}$ in $\mathrm{EE}$, the use of theory involves the substantial theoretical frameworks, available and applied EE researches. These frameworks include typology of different processes that are concerned with changes in oriented approach. These theories aretargeted to ascertainappropriate actors plus interactions through an increased capability towardsstimulating changes in EE (Beanland et al., 2013; Al-Atabi, 2014). Fortunately, a variability of techniques exists in integrating theories into a variation research objective, providingunlimitedelasticity to modify proxies, thereby underpinning that there is no unusual and appropriate method in making theory to be operational in EE research (Grasso et al., 2010; Chan-Hilton et al., 2019). The combination of theory thatstimulates changesin engineering is as a result ofnurturingthe EEactivities of the institution, which gives a significant illustration of date-to-dateinitial stages of random changes in EE. This has brought effectiveness and becomes a plethora of research explored in engineering, that has remained basically dissociated from changes in EE initiatives and practices (Goldberg et al., 2014; Chan-Hilton et al., 2019). Leveraging theories in EE emerges from advancement and technology impact manufactured from resulting literature, in producing magnanimous
Blue Eyes Intelligence Engineering and Sciences Publication

(C) Copyright: All rights reserved.

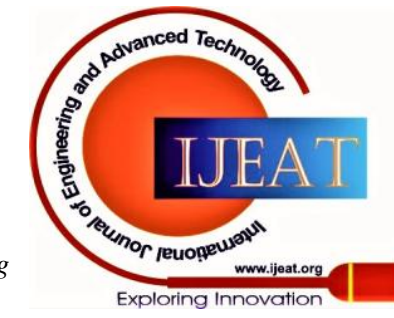




\section{Chaos Theory as Relevance for Engineering Education in the Era of the Fourth Industrial Revolution in Africa}

outcomes in research changes. This will move forward the CT relevance for EE (Al-Atabi, 2014).

Hence, it will play an important role in making engineering educators to demonstrate their skills to be effective in engendering change in EE. Several studies (Grasso et al., 2010; Judrez, 2011; Chan-Hilton et al., 2019) have identified the use of hypothetical engineering models in bringing changes in efforts that are characterized by three areas. First, theory can be propagative, which means that theory can be used as a priori in guiding the formation and sustainedexpansion of change in EE improvement. Thus, propagativeapproach in undertaking the standard appraisals in $\mathrm{EE}$ is basic in a rational system. Second, theory use can be logical, as it is used in directing day-to-day engineering activities. And, the third aspect is that the hypothetical circumstances can be philosophical, by offering a lens through which understanding and communication brings changes and application of 4IR skills in EE (WEF, 2009; 2017). Similarly, these theories used in three parts do not necessarily need to be identical as engineers may one assumptions before the other one, as a means ofspawning changes in the early structure of engineering tasks, but to find another better rational theory that will accommodates engineering practices(Akmansoy et al., 2014).

Exploring how Chaos Theory enhances relevance in Engineering Education

CT is a mathematical theory of non-linear which displays circumstances and randomness with a stimulating structures that are unavoidably used in enhancing EE. CT in various capacity with non-equilibrium dynamics has a complex changing aspects in an anticipated unpredicted pattern that revealed an unreliable designs(Nehmzow et al., 2005; Eduardo et al., 2012). Thus, CT can be used to explain the seemingly randomnessor disorder in a deterministic basic engineering structure, designated and examined through means of differential equations with uncertainty(Ovchinnikov et al., 2016; Wolf-Branigin, 2013;Heylighen, 2008). Although, complex system theory has been formally originated from natural sciences and mathematics, gaining substantial traction in the engineering sciences. This has helped in explaining social engineering phenomena, that will advance the social system inquiry that will offer avenues to engender change in complex systems (Cvetek, 2008; Boeing, 2016). In EE, various recommendations and frameworks were derived from complex theory, which can be expended in formation, operation, and communication in EE in the 4IR era. With 4IR engineering tasks and curriculum in EE, typically focuses on 20th century activities, associated with outdated engineering designs, and manufacturing. Although, engineers made impact in the 20th century, however, the 21st century engineers have been engaged in performing and engaging with experts from multiple fields (WEF, 2017; Chan-Hilton et al., 2019; Okulov, 2020). Though, Chaos was assumed to be avoided in reality of life, asthe situation of the world engineering industries are exposed to the 21st century ideology and skills. Conversely, this will lead to production of new technologies, in the changing nation's economy in assisting the society to adopt new technologies (Boeing, 2016; Chan-Hilton et al., 2019). Therefore, engineers will need to influence their completion with their global counterparts and develop an entrepreneurial attitude towards production. Engineering no longer functions in a void, or separated from the society, but provide communicative, creative and interdisciplinary capabilities, with flexibility in accommodating easy mobility and adaptability, becoming increasingly imperative for $\mathrm{EE}$ students (Wolf-Branigm, 2013). This will involve major pedagogical changes, that will introduce integrated problemand challenge-based learning around CT significance in EE. Also, the global perception of CT is interconnected with created changes that are inevitable, as restructuring curriculum are advocated to transform the increasing request of contemporary engineers, in order to make optimum use of new academic approaches(Iqbal et al., 2015 ;Graham, 2012; Goldberg et al., 2014). Curriculum restructuring should not affect technical depth, that will endanger EE strengths, scientific research and expertise in engineering field. For instance, waves or movement in water or in the midst ofa large group of people, showed an irregular outcomes with a perceptible identity of CT, but in an unsystematicand predictable compositions. On the other hand, secured complex systems are predictable and have continuous vigour with strength (Lorenz, 1972). Besides, the scientific and engineering community has accumulated greater information capacities in predicting CT phenomena in EE. Engineering curriculum can be science-and-research-based that will enhance and widen the student horizon. Hence, EE are required to assist engineering students to think in a bigger picture and contexts that will influence objectives, process and research outcome or design (Beanland et al., 2013).

The Principles of Chaos Theory works to improve the relevance of Engineering Education

The resulting claims of CT to engineering principles are conceivablein the past asits presentation with quite a few explanations, have the capacity in redesigning and producing acceptable engineering principles in EE. The inherently unpredictable state of EE system show a deep and established fluctuating sensitive changes that can cause unexpected absolute results, thus giving an expression of randomness(Boeing, 2016). Thus, CT suggests that the near balance state may seem consistent, but whendivergence occur in engineering projects, engineers take it upon themselves to see the underlying factors that trigger deviations. The divergence intensely, reproduces disintegration that is cutting edge in new engineering built systems with specified creation of firmness through response hoops in EE. Moreover, new engineering built systems with higher software applications are sometimes not fully embraced in EE, as it requires new skills and in-depth knowledge to have it in operation.In EE, CT reveals equilibrium insight as a key and central concept in engineering, providing a limited number of processes to demonstrate definable equilibrium state (Englund, 2009). Remarkably, CT applications occur in technical domain that represent the power house of EE that are centred on paradigm shift in engineering research. Significantly,

Published By:

Blue Eyes Intelligence Engineering

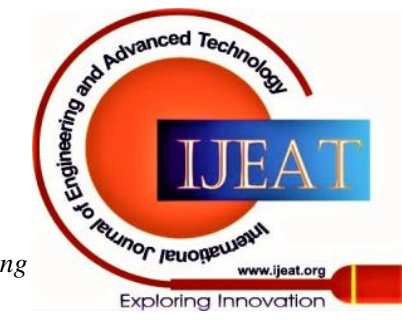


the evaluation of CT has been recognised as a model that can build on a new engineering methods that will aid in redesigning engineering software and hardware components in engineering specialty. EE provides professionals the technical designing of manufactured machines that will invent engineering skills to design modified techniques that will develop the coordinating programmes that has a special-purpose function(Goldberg et al., 2014). As many of the designed modified techniques are created with a paradigm shifting in a multi-dimensional patterns are associated withan outdated concepts of technological theories. This method will aid in driving EE to a high level of indulging in emergence research, changing from time with an unpredicted constitutive parts. Therefore, the modern engineers are beginning to engage in collaboration research that will bring to table innovative ideas that will change the entire strategies in EE(Grasso et al., 2010; Graham, 2012). In particular, 21st century engineering students are becoming rooted in knowledgeable and practical projects that brings to conclusion a significant means in resolving a huge complex system of engineering problems. The application of CT in EE teaching in engineering classes will enhance learning and will reinforce universal approaches to human communications, that will encourage cultural variety. As this philosophies multidimensional in engineering tasks (Eduards et al., 2012). CT has affirmed that and view. This assist learning among engineering students. CT validated and pedagogical problem can be used to transform the linearpossession unchanging that has complex and unified (Babaei, 2013;Wang et a., 2012). Similarly, engineering educators have projected the benefits of investing in EE, as they have suggested the relevance of $\mathrm{CT}$ to be consolidated in understanding engineering research that will assist in reducing the patterns of errors in engineering industrial projects(Boeing, 2016; Chan-Hilton et al., 2019). Thus, the pursuit for thestability and CT relevance in EE has attract a different dimension of teaching and learning as it is associated with a multi-faceted and dynamic system of broad interrelated patterns in engineering fields. Hence, engineering classroom should be an open, and operated in a non-linear system, that must be portrayed with a flexible choice of simplicity, unlikelihood, and consistency(Okulov, 2020).

\section{THEORETICAL FRAMEWORK}

This paper employed Chaos theory (CT) as a theoretical framework, which was adopted from the 'butterfly effect', propounded by meteorologist Edward Lorenz (1961) when carrying out a weather forecasting research. Although, Prigogine and Stengers (1984) incorporatedCTwhile JamesGleick (1987) popularized CTin their research field work. The theory posited that initial effects with similarities have huge insignificant instabilities that are dominant owing to the equivalence applied to science of nature and humanities excluding weather science. Therefore, EE are built on active systemic assumptions with an equilibrium stages of pursuing constant change in incorporating constant change. The guiding general principles of CT are laid in an abstracted ideas which determine its creative skill in an unconventional manner (Lorenz, 1972). This theory can be applied to show how the principles of CT can enhance its relevance for EE in 4IRE. as it highlight the perspectives of chaotic components in order to restructure EE. In Africa, EE has been accounted for low quality and poor relevance, in spite of a lot of significant efforts that has been contributed to EE (Prigogine et al., 1984; Forgues et al., 2019). Besides, mapping engineering perspectives in EE, allows increased intellectualdebates based on social different opinion,and interpretations that has a conventional design based on a theoretical philosophy, that focused on accurate and precise systemic responses(Heylighen, 2008). The generalization of the hypotheticalparadigm shift with its occurrence in a behavioural array, has a strong flexible practical tides and randomness (Iqbal et al., 2014; 2015). The importance of CT in its explanatory power is to allow an understanding of diverse behaviouralsystems, via unpredictable observation and experimentation. These are, labelled as error or divergence with a tagged patterned and representativebehaviour in EE. Hence, CT may enhanced EE and relevant system application may be valued according to its worth and variations, as chaosprepositions is allegedto have been scrutinized and benefitted engineering students inscrutinizingengineering arraysoutside a complex system (Lorenz, 1972; Prigogine et al., 1984; Forgues et al., 2019). It is not inconsequential that engineering institutions are capable of accommodating rapid changes in educational systems, intensive research institutes, reflected as leadingspaces to followphilosophical thinking (Secules et al., 2018). Presently, many intensive academia on CT relevance are not domesticated in engineering undergraduates programmes or neither modern curriculum areadjustedto 21st century knowledge-based and engineering skills(Chan-Hilton et al., 2019). Yet, together they are crucial for invention. It is the objective of engineering educators to facilitate engineering undergraduates to maximize their prospective contributions to the extensivehumanity and make a global transformation through creative working solutions.

\section{DISCUSSION}

The development of CT in EE is a welcome idea that is open for rapid advancement and expansion in engineering. Thus, the relevance of CT has generatedhypotheticalparadigms which has created complex systems of engineering programmes that are key in engineering profession. The research and development in EE have attracted collaboration research through a systematically organized body of knowledge about a particular engineering subjects(Edward Lorenz), (Benoit Mandelbrot), (Mitchell Feigenbaum). The illustrations of CT principlesprovides technologicaldiagrams that aid in delivering CT functional, and non-linear, which may result in randomdivergence as it is pointed to each learner in engineering domain (Lorenz, 1972; Heylighen, 2008; Englund, 2009; Forgues et al., 2019). Moreover, insignificantpreliminary differences has pushed forward to give rise to impulsiveoutcomes, with irregulardivergence,
Plue Eyes Intelligence Engineering and Sciences Publication

(C) Copyright: All rights reserved.

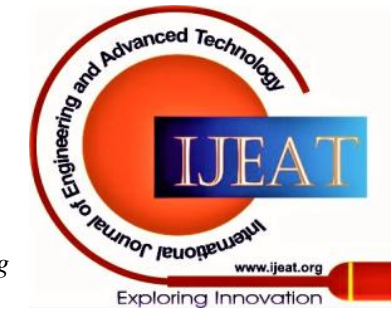




\section{Chaos Theory as Relevance for Engineering Education in the Era of the Fourth Industrial Revolution in Africa}

as it is carried out with earlypositions that may affect learning, and the processes are replicated at diversebalances in EE(Eduards et al., 2012).

Engineering undergraduates are not just students of engineering, but of problemsolvers, which may go well afar from technologicalcapability, which generally, has a logical and diverse relationship with educators and profession(Graham 2012; Lucas, 2014). Engineering educators should make a lot of efforts in empowering engineering students to have aprofessional and topnotchresilient ofabilitiesby means of developmentof having knowledge as most important factor in EE(Grasso et al., 2010). The intermediary role between CT and engineering education are multifaceted as it will show a great deal of knowledge, awareness, or intelligence in modern engineering field. The application of CT in EE will promote peripheries of innovations that will lead to progress in synthesizing engineering students to enable them to engage in acquisition of self-skills development. Most significantly, engineering students should be equipped with unique learning abilities that will aid them in understanding the dynamic interrelationship that enhances the relevance of CT in EE(Beanland et al., 2013). EE are in a position to integrate CT principles, which has been used in conveying knowledge-basedtechnical designs to teaching and learning platforms that are serves as prerequisites in engineeringprogrammes. Thus, engineering thehypotheticalunderstanding in anadvancedway could promote the relevance of $\mathrm{EE}$ in building a group ofcontemporary scholars in engineering academia and industrial profession(Grasso et. al., 2010; Graham, 2012).EE can be embraced from a various body of knowledge where students can applied the principles of CT inEE, through multidimensional means of equipping and building engineering institutions. This will further resolve issues related to the needs of complex systems that are randomly produced in the process of incorporating the principles that will foster skill development among engineering students (Graham, 2012; Goldberg et al., 2014). In addition, amplificationof theunlikelihoodof skill development menace, explanations familiarizing significancesinitiated. Hence, development of skills can be interpreted in engineering that will require training and experiences from professionals to work with engineering educators to improve the curriculum in engineering(Chan-Hilton et al., 2019).Predominant applications of CT ethics in EE, in connections, with multi-dimensional and selfmotivatedbehavioural tendencies of engineering studentsyIII. will enable them in acquiring modern skills that will assist them in meeting up with their counterparts globally.Though, EE mechanismsrequire keycertain positions that areabsolutely unique in building and incorporating CT relevance in engineering curriculum that that will completely enhance the outcomes of engineering graduates(Okulov, 2020). The over-simplification of multifaceted engineering programmes andexistenceof misconstructions in engineering academicsshould allow engineering educator's experiences in teaching various applications of CT, and as a result will aid in developing models for engineering curriculum and programmes(Secules et al., 2018;Beanland et al., 2013). Therefore, EE will go a long way to help engineering students to think about their careergoals, and dynamic strategiesthat will significantenhanced EE with developing abilities, relationship understanding, social and responsive intelligence that will produce outstanding engineering students(Lucas, 2014). Hence, engineering beginners will be skilled to be flexible in handling engineering matters and as well motivate them to work collaboratively that will make them to learn how to communicate with the public engineering domain, as its significance is projected towards an advanced technological and engineering professions (Lorenz, 1972).

\section{The Implication of Chaos Theory relevance in Engineering Education}

Presently, EE is deeply rooted in the principles and standard of preceding determinism and it has been frequently underscored in changing proportional of the linear relations in an undeviating systemicphilosophyestablishedas well asintroduced engineering programmes and curriculum(Forgues et al., 20919). The requirement is that it ignores many observed complex dynamics as it cannot explain them. CT is an interesting new area of modern science, used in convertingindulgent of the engineering domain. The seeming inconsistency of chance emerging in unassuming deterministic schemes has been making researchers consider that an understanding of deterministic chaos might rationalize the nonconformities between logical projections and tentativeoutcomes(Okulov, 2020). Deterministic chaos can be included in the engineering curriculum and learning materials at different levels and in several ways. In EE, major concepts of chaotic dynamics can be reintroduced and chaos-based modelling of reductionistic method, may prove useful. The incorporation of CT relevance for EE will develop complete and dynamic philosophy instead of reductionistic passive thinking. This will encourage multi-disciplinary studies and promote synthesis and analysis in EE research. Engineering educators should nurture analytical thinking skills as well as creative skills, which will reimagine the EE curriculum. Hence, engineering educators as well as professionals in 4IRE recognizes engineers need to work in teams, talk with several consultants in meetings, and engage themselves in effective public policy debates in regular sessions in the future. In the face of pressure in EE, EE needs to step up to meet with challenges of providing the broader CT modelling education to engineering students respectively.

\section{CONCLUSION AND RECOMMENDATIONS}

This paper attempts to show that in Africa, CT relevance for $\mathrm{EE}$ in the 4IR era, which is very imperative in improving advancement and quality of engineering graduates at their different career stages. Thus, CT development and its relevance for EE has reflected a simple model that matches the needed EE requirements and skills in 4IR era. CT has showed from review that it has relevance for EE, as more significantly acting as a paradigm shift in engineering programme of study.

Published By:

Blue Eyes Intelligence Engineering

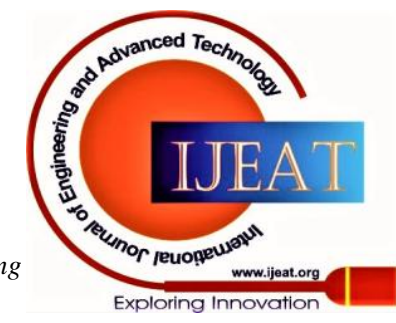


Hence, the enhancement of hypothetical perception involving scientific principle to explain the relevance of CT in EE that will form the knowledge-based specific tasks.

Several authors have clearly explored CT application to EE learning platforms as it has been considered acceptable in engineering hypothetical propositions. The engineering faculty should be conversant through CT, and additional research studies are able toconduct in order to structure CT in the engineering curriculum to instill relevance in EE. In addition, the transformation of EE curriculum, can be linked to a theoretical paradigm, that is built on CT.This can serve as an educational tool that will integrate and incorporate knowledge perspectives from several collaboration methods put in transforming engineering curriculum. Hence, closing the gap of CT relevance for $\mathrm{EE}$, is of critical importance in Africa as failure to accommodate CT in EE will result to poor quality EE. CT can be instilled in the engineering curriculum and programmes undergoing substantial scrutiny and perhaps, provide more effective means to explore CT applications in engineering teaching and learning in the4IR era. Therefore, key recommendations are advocated as follows:

1. Prospective engineering educators should be provided with available opportunities that will support consideration and utilization of alternative engineering paradigms when dealing with complex chaotic systems in the engineering classroom in order to equip students with better and enhanced learning facilities.

2. Engineering educational educators and relevant stakeholders should prepare themselves and provide appropriate information to address non-linear disproportional effects in EE systems, which will recognize the effects that are not necessarily traced tothe simple foundations within the engineering complex systems, thereby identifying simple reasons for potential exponential effects.

3. Engineering educators should make efforts to view the tendency for 'butterfly effect' incidents that commence at engineering classes, in which educators should acquire more knowledge of the surrounding community as well as the social learning engineering environment of the institution as soon as possible.

4. Curriculum models using CT should be created to connect curriculum, learning materials, instructions and assessment using CT principles as a foundation. This will allow for development of a chaos model for EE that possibly willbe influenced by anaddition of chaos characteristics,besides commitments of engineering educators and students as well as professionals.

\section{REFERENCES}

1. Akmansoy V, Kartal S (2014). Chaos theory and its application to education: Mehmet akifersoy university case., Educational Sciences: Theory and Practice; 14 (2): 510-518.

2. Al-Atabi M (2014). Think Like an Engineer: Use systematic thinking to solve everyday challenges \& unlock the inherent values in them; Taylor's University, Selangor, Malaysia.

3. Babaei M (2013). A novel text and image encryption method based on chaos theory and DNA computing". Natural Computing; 12 (1) 101-107.

4. Beanland D, Hadgraft R (2013). Engineering Education: Transformation and Innovation; Melbourne, Vic.; RMIT University Press.

5. Boeing G (2016). Visual Analysis of Nonlinear Dynamical Systems: Chaos, Fractals, Self-Similarity and the Limits of Prediction. Systems; 4 (4): 37.

6. Borrego M, Froyd J, Foster M (2015). What is the State of the Art of Systematic Review in Engineering Education? Journal of Engineering Education; 104 (2): 212-242.

7. Brown PR, McCord RE, Matusovich HM, Kajfez RL (2015). The use of motivation theory in engineering education research: a systematic review of literature. European Journal of Engineering Education; 40 (2): 186-205.

8. Chan-Hilton A, Morelock JR, Ingram E, Utschig T (2019). Connecting Theory with Practice: Four Change Projects in Faculty Development for Engineering. Paper presented at the ASEE Annual Conference \& Exposition, Tampa, FL.

9. Cvetek S (2008). Applying chaos theory to lesson planning and delivery, European. Journal of Teacher Education; 31 (3): 247-256.

10. Eduardo L, Ruiz-Herrera A (2012). Chaos in discrete structured population models". SIAM Journal on Applied Dynamical Systems; 11 (4): 1200-1214.

11. Englund RL (2009). Applying chaos theory in a project based organization. Paper presented at PMI ${ }^{\circledR}$ Global Congress 2009EMEA, Amsterdam, North Holland, The Netherlands. Newtown Square, PA: Project Management Institute.

12. Forgues B, Thietart R-A (2019). Chaos Theory. Palgrave Publishers Ltd.

13. Gleick J (1987). Chaos: Making a New Science. National Book Foundation, National Book Awards. Accessed on 24th September, 2020.

14. Goldberg DE, Somerville M (2014). A Whole New Engineer: The Coming Revolution in Engineering Education; ThreeJoy Associates Inc., Douglas, Michigan.Graham, R (2012). Achieving excellence in engineering education: the ingredients of successful change. The Royal Academy of Engineering.

15. Gough D, Oliver S, Thomas J (2017). An introduction to systematic reviews. London: SAGE.

16. Grasso D, Burkins MB. (Eds.) (2010). Holistic Engineering Education, Beyond Technology, Springer Verlag, New York, 2010.

17. Heylighen F (2008). Complexity and self-organization. Prepared for the Encyclopedia of Library and Information Sciences, edited by Marcia J. Bates and Mary Niles Maack (Taylor and Francis); Pp. 1.18.

18. InêsDoreito SC, Manish M (2019). The study of grit in engineering education research; a systematic literature review. European Journal of Engineering Education; Pp. 1-26. doi 10.1080/03043797.2019.1688256.

19. Iqbal S, Zang X, Zhu Y, Chen YY, Zhao J (2014). On the impact of moocs on engineering education, in: MOOC, Innovation and Technology in Education (MITE), 2014 IEEE International Conference on, IEEE, 2014. Pp. 101-104

20. Iqbal S, Zang X, Zhu Y, Hussain D, Zhao J, Gulzar MM, Rasheed S (2015). Towards moocs and their role in engineering education, in: 2015 7th International Conference on Information Technology in Medicine and Education (ITME), IEEE; Pp. 705-709.

21. Juárez F (2011). Applying the theory of chaos and a complex model of health to establish relations among financial indicators. Procedia Computer Science; 3: 982-986.

22. Lorenz EN (1972). Predictability: does the flap of a butterfly's wings in Brazil set off a tornado in Texas? 139th meeting of the American Association for the Advancement of Science, 29 December.

23. Lucas B (2014). Thinking like an engineer: Using engineering habits of mind to redesign engineering education for global competitiveness; Proceedings of the 42nd Annual SEFI Conference, Birmingham 15-19 September 2014,;

24. Nehmzow U, Keith W (2005). Quantitative description of robotenvironment interaction using chaos theory. Robot and Autonomous Systems; 53 (3-4): 177-193.

25. Okulov AY (2020). Structured light entities, chaos and nonlocal maps". Chaos, Solitons \& Fractals.;133 (4): 109638.

26. Ovchinnikov IV, Schwartz RN, Wang KL (2016). Topological super symmetry breaking: Definition and stochastic generalization of chaos and the limit of applicability of statistics". Modern Physics Letters B.; 30 (8): 1650086

27. Prigogine I, Stengers I (1984). Order Out of Chaos. New York: Bantam.

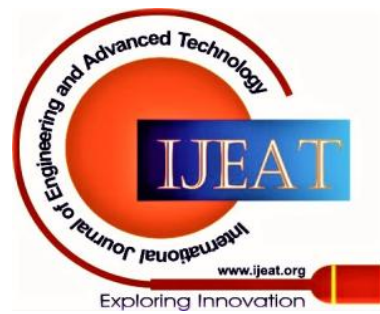


Chaos Theory as Relevance for Engineering Education in the Era of the Fourth Industrial Revolution in

\section{Africa}

28. Secules S, Bale JJ Jr., Sochacka NW, Walther J (2018). Examining a Novel Theory-to-practice Effort in Engineering Education through Multiple Theoretical Lenses of Systems and Change. Paper presented at the 2018 ASEE Annual Conference \& Exposition, Salt Lake City, UT.

29. Torres-Carrion PV, Gonzalez-Gonzalez CS, Aciar S, RodriguezMorales G. (2018). Methodology for systematic literature review applied to engineering and education. 2018 IEEE Global Engineering Education Conference (EDUCON), Tenerife. Pp. 1364-1373.

30. Wang X, Zhao J (2012). An improved key agreement protocol based on chaos. Commun. Nonlinear Sci. Numer. Simul.;15 (12): 4052 4057.

31. Werndl C (2009). What are the New Implications of Chaos for Unpredictability? The British Journal for the Philosophy of Science; 60 (1): 195-220.

32. Wolf-Branigin M (2013). Introduction: The History and Theory of Complexity. In M. Wolf-Branigin (Ed.), Using Complexity Theory for Research and Program Evaluation. Oxford: Oxford University Press.

33. World Economic Forum (WEF), (2009). The global gender gap report 2009.

34. World Economic Forum (WEF), (2017). Insight Report: The global gender gap report. 2017. Accessed from 12th September from http://www.weforum.org/docs/WEF_GGGR_2017 .pdf.

\section{AUTHOR PROFILE}

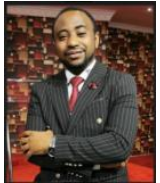

Dr. Kehdinga George Fomunyam, Institute for Systems Science, Durban University of Technology, Durban, South Africa.

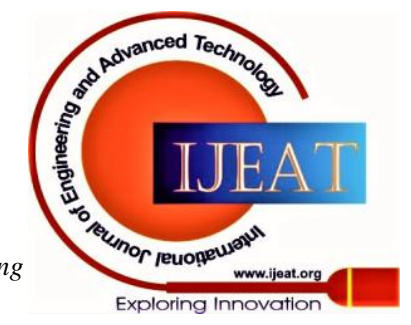

